\title{
Cigarette use attitudes and effects of acculturation among Arab immigrants in USA: A preliminary study
}

\author{
Linda Haddad ${ }^{1^{*}}$, Omar El-Shahawy $^{2,3}$, Kawkab Shishani ${ }^{4}$, Hala Madanat ${ }^{5}$, \\ Sukaina Alzyoud ${ }^{6}$
}

${ }^{1}$ Department of Family and Community Health \& Institute for Drug and Alcohol Studies, Faculty of Nursing, Virginia Commonwealth University, Richmond, USA; ${ }^{*}$ Corresponding Author: lhaddad2@vcu.edu

${ }^{2}$ Department of Social and Behavioral Health, School of Medicine, Virginia Commonwealth University, Richmond, USA

${ }^{3}$ General Medical Management, Ain Shams University, Cairo, Egypt

${ }^{4}$ Washington State University, Spokane, USA

${ }^{5}$ Graduate School of Public Health, San Diego State University, San Diego, USA

${ }^{6}$ Hashemite University School of Nursing, Zarqa, Jordan

Received 18 August 2012; revised 16 September 2012; accepted 28 September 2012

\begin{abstract}
The purpose of this study is to explore cigarette use patterns, which include current use, beliefs, attitudes, attempts to quit, and acculturation, among Arab immigrants. A sample of self-identified Arab immigrants (221) living in the Richmond, VA metropolitan area was recruited from Middle Eastern groceries, restaurants/lounges, and faith and charitable organizations. Men in this sample had higher rates of cigarette smoking (67.6\%) than the rest of the general adult US population. Many smokers in the study had the desire to quit and had made attempts to quit. Further analysis of acculturation in relation to the risk of not considering quitting was performed using logistic regression. The older an individual was when he/she moved to the US $(O R=0.93$, $\mathrm{Cl}: 0.87,0.98)$ and the more time an individual had spent in the US (OR $=0.93, \mathrm{Cl}$ : $0.88,0.98$ ) contributed significantly to the least number of quit attempts. Further random sampling and study is needed to confirm the high prevalence of tobacco use among this minority group.
\end{abstract}

Keywords: Arab Immigrants; Tobacco Smoking; Acculturation; Minority Smoking

\section{INTRODUCTION}

Tobacco use remains the leading cause of preventable morbidity and mortality in the world [1,2]. In the United States, tobacco use has been declining at a slower pace than expected despite the increased taxation and more stringent tobacco policies that have been put into place [3]. In 2000, the Healthy People 2010 initiative aimed at reducing the rate of tobacco use in adults to $12 \%$ by the year 2010 [4], but it only succeeded in reducing the rate to $20.6 \%$ [5]. This obvious failure in achieving this target forced the continuation of this target by keeping it as part of the Healthy People 2020 initiative. In order to accomplish this new set goal, smoking has to be addressed among all sub-populations especially those with a higher smoking prevalence than the general population [5].

One of the minority populations with high tobacco use rates is Arab immigrants [6,7]. But we do not have accurate national data on the prevalence of smoking among Arab immigrants; however, a number of randomly selected samples of Arab immigrants living in the state of Michigan suggest that the prevalence is quite higher than the US average of 20\% [6-8]. Rice and Kulwicki [9] studied adult Arab immigrants residing in the Detroit metropolitan area; they found that $40.6 \%$ of the men and $38.2 \%$ of the women surveyed were smokers. One potential reason behind the high smoking rates that were found in these studies might be the fact that tobacco smoking prevalence in Arab countries is very high compared to the US. The rate of smoking prevalence in adult men is around 50\% in Tunisia, Lebanon, Iraq, and Yemen [2]. Moreover, immigrants may disproportionately benefit from existing cessation programs that may not have existed or have been accessible in their home countries [2].

One important aspect to consider is the fact that Arab immigrants are living in a new culture, and cultural adjustment (or acculturation) exhibits some influence on their behaviours. To our knowledge, acculturation, specifically how it impacts health behaviour, has been exhausttively studied in specific immigrant populations: Hispanics and South East Asians [10-13]. However, only limited efforts have been developed to attempt to capture acculturation in immigrant Arab populations in the USA [14]. It is empirically relevant to try to understand how 
this immigrant group adjusts their behaviour to live in the US and how this adjustment affects their smoking habits $[15,16]$. To accomplish this task, we need to make sure that we fully understand acculturation and its measurement.

Lara and colleagues [17] identify acculturation as the acquisition of different cultural elements of a dominant society, which is often measured using proxy indicators. These indicators are not directly related to the measurement in question because measuring the degree of acculturation in immigrant groups is very difficult. Therefore, researchers use the main indicators as proxy indicators for the impact of acculturation on health behaviours, including smoking. These proxy indicators might have less predictive validity than using validated instruments. However, it is widely accepted in acculturation research and health behaviour [18-23]. The main indicators are length of stay in USA, proportion of life spent in the USA, language spoken at home, and the first language spoken. The rate of tobacco use among immigrants may change as they become "more acculturated". The effect of acculturation on smoking is not uniform and may even differ from men to women within the same immigrant population [17]. For example, previous research on Korean immigrants indicates that rates of tobacco use among men declined by half while those of women increased after immigration [24]. A similar finding was reached among Mexican American populations [25].

We found limited research that assessed quitting behaviour in immigrant populations [26]. One of the important aspects to assess is the number of serious quit attempts. This is a very important indicator of an individual's readiness to quit and abstain from actual tobacco use. Research shows that a smoker typically quits smoking only after numerous serious attempts to quit. Relapses are common as are fresh attempts to quit [27,28]. Another aspect to assess in immigrant populations would be the daily use of cigarettes. One study found that daily use of cigarettes was higher in more acculturated Hispanic males than less acculturated males [29].

Over the last fifteen years, studies have examined the prevalence and incidence of tobacco smoking and tailored cessation programs among key immigrant populations that exhibited a greater risk for smoking; however, Arab immigrants in the US were not as thoroughly studied as other key immigrant populations [13,24,25]. Arab immigrants are one of the fastest growing immigrant groups in the US, mainly due to the war and political unrest in the Middle East [30]. Globalization and high migration make it economically and socially important for governments to understand how members of immigrant groups adjust to the cross-cultural interaction. It is in the interest of governments to understand this phenomenon as it affects the global workforce, particularly with regard to health behaviour [11,31]. It then seems logical that some ethnic minorities have smoking rates much higher than the general US population [22,33]. A previous study focused on Arab immigrants from the Midwest and measured acculturation and smoking within this population; it found that more acculturation implied less nicotine dependence among subjects of the study [15]. Thus, future research is needed to explore smoking behaviour in understudied ethnic minorities (i.e. Arab immigrants). Moreover, better understanding the interaction of acculturation will help researchers in their attempts to improve tobacco prevention and cessation activities [34]. Acculturation and its interaction with smoking can be measured in a very structural way [15] or through using proxy indicators that would provide an easier tool for acculturation measurement. In a previous study, substance use among immigrants was assessed through the data of the national health interview survey with time spent in the US as the proxy measure for acculturation. It is very well known that exposure to the host environment is considered the best proxy indicator for acculturation when other psychometric scales are not available [15,17].

Thus, the purpose of this study is to explore the cigarette use patterns including current use, beliefs and attitudes, and acculturation among Arab immigrants in the Richmond, VA metropolitan area. The identification of tobacco use and other related patterns that would be identified here may help facilitate the development of community based interventions targeting tobacco use and would be sensitive for Arab immigrants in future research.

\section{METHODS}

\subsection{Population and Study Sample}

The study team used a convenience sampling technique to recruit the participants from the Richmond metropolitan area (Richmond city, Chesterfield County, Henrico County, and Hanover County). Participants volunteered in response to a widespread advertisement through local media, social networking, and fliers distributed in Middle Eastern grocery stores, restaurants, lounges, and faith-based organizations in Richmond. The content of the ads in our study was an invitation to participate in a survey about smoking habits among Arab immigrants. Current smokers, former smokers, as well as those who had never smoked were welcomed as participants. Participants were either approached in places where a social interaction could have been possible (Ex: Islamic cultural centre) or they contacted the number in the ad where the research assistant responded and scheduled appointments to meet the participants. On occasion the principle investigator (PI) of the study responded to the participants and scheduled appointments as well. The participants filled 
in a self reported questionnaire while the research assistant was vailable to answer any questions that they would have had. The screening process to be included in the study was done over the phone when participants called to show interest of participation. Inclusion criteria were being older than 18 years of age, being from a country of Arabic origin, and reading and speaking either Arabic and/or English language up to fluency level to be able to fill in a self reported questionnaire. Even though all participants asked for the English version, we had the questionnaires of the study available in both languages.

\subsection{Data Collection Procedure and Sites}

The ethical approval was obtained from the Virginia Commonwealth University Institutional Review Board. The research assistant and/or the PI conducted short initial ten minute interviews over the phone to make sure that participants met the inclusion criteria. The research assistant and the PI are both Arabic/English bilingual. The same research assistant approached participants in a number of convenient locations, such as mosques and the Islamic cultural centre in Richmond that were known to host large numbers of Arab immigrants in the area. Upon the participants' agreement, they were given the questionnaire and were asked to fill them out these locations. The average amount of time spent to fill out a questionnaire was around 20 minutes. Data were collected from June 2010 through December 2010. All participants signed a consent form; there was no identifying information on any of the tools used. Participants did not receive any compensation for participating.

\subsection{Measures}

The study measures that were used are composed of the following:

Demographic and cultural Information (DCI) [35]This is a 21-item instrument form that was used to obtain background and cultural information about the participants: age, gender, occupation, country of origin, income, primary language spoken, and whether or not they lived with one or more family members who smoked. Tobacco Use Questionnaire (TUQ) [36]-This 32-item questionnaire asks about smoking history, smokeless tobacco use, smoking habits, past attempts to quit smoking, attitudes and beliefs towards tobacco use, and the desire to quit. In addition, the last four questions measured the stage of change: if the subject is planning on decreasing their tobacco use in the next week, month, six months, or one year and whether he/she is trying to stop smoking. The questionnaire was previously used by Haddad and Petro (2006), and it showed a high level of validity and reliability [35]. The internal consistency of the tobacco use questionnaire was 0.79 . The results of questions pertaining to water pipe use are not presented in this paper.

Acculturation Indicators: For the purpose of our study, three indicators of acculturation were used: 1) Number of years in USA, which was computed as the participant's current age minus the participant's age when he/she entered USA for immigrants not born in USA; 2) The language spoken at home. To assess the language spoken at home, participants were asked "what language do you speak at home?” And 3) first learned language, which was assessed by asking "what is the language of your mother tongue?"

All instruments were translated from English to Arabic and then translated back from Arabic to English. The translated version had reliable and valid findings [7,9]. Bilingual English/Arabic instruments were used in this study; however, all participants used the English version of the questionnaire at their own discretion.

Analysis:

A JMP version 10 statistical package was used to analyse the data of the study. Relevant statistics were calculated for the entire sample and stratified according to age, gender, country of origin, and smoking status when applicable. Relevant statistics were calculated for the entire sample and stratified according to age, gender, country of origin, and smoking status. First we calculated univariate statistics to describe the sample. Second, we used multivariate logistic regression to examine the acculturation indicators and their effect on the number of cigarettes smoked per day and on the number of serious attempts to quit. All data were examined regarding distributions and trends in the data, and the level of significance was set at the $\mathrm{p}<0.05$ level.

\section{RESULTS}

\subsection{Sample Characteristics}

This study enrolled 221 Arab immigrants living in the Richmond, VA metropolitan area. Table 1 describes characteristics of the study sample for both smokers and non-smokers. The participants included males (56.8\%) and females (43.2\%). The average age was 28.4 years ( $\mathrm{SD}=10.3$ ), and ages ranged from 18 to 60 years old.

$69 \%$ reported being current smokers, defined by having smoked at least one cigarette per day during the past 30 days. Smoking rates were higher for men than women (67.6\% and, $32.2 \%$ respectively). With regard to the country of origin of birth, those who were born in Iraq or had parents who were born in Iraq had the highest smoking rates (25\%) when compared to individuals from other Arab countries of origin. When asked about family members who smoked, fathers were the most likely to be reported as smokers (66.4\%). 
Table 1. Demographic characteristics $(n=221)$.

\begin{tabular}{|c|c|c|c|}
\hline & $\begin{array}{c}\text { Smokers } \\
(\mathrm{n}=152) \\
\mathrm{n}(\%) \\
\end{array}$ & $\begin{array}{c}\text { Non-smokers } \\
(\mathrm{n}=69) \\
\text { n (\%) }\end{array}$ & $\begin{array}{c}\text { Overall sample } \\
(\mathrm{n}=221) \\
\mathrm{n}(\%)\end{array}$ \\
\hline Age (mean, SD) & $27.9(10.0)$ & $29.4(10.8)$ & $28.4(10.3)$ \\
\hline \multicolumn{4}{|l|}{ Gender } \\
\hline Males & $101(67.6)$ & $23(33.3)$ & $124(56.8)$ \\
\hline Females & $48(32.2)$ & $46(66.6)$ & $94(43.2)$ \\
\hline \multicolumn{4}{|c|}{ Father's country of birth } \\
\hline Iraq & $40(26.3)$ & $25(36.2)$ & 65 (29.4) \\
\hline Gulf countries & $37(24.3)$ & $12(17.9)$ & 49 (22.1) \\
\hline Syria & $20(13.1)$ & 11 (15.9) & $40(18.1)$ \\
\hline Egypt & $16(10.5)$ & $8(11.5)$ & $28(12.6)$ \\
\hline North African & $8(5.2)$ & $5(7.2)$ & $21(9.5)$ \\
\hline Yemen & $1(0.5)$ & $8(11.5)$ & $16(7.2)$ \\
\hline Mauritania & $1(0.5)$ & - & $1(0.5)$ \\
\hline Somalia & $20(13.1)$ & - & $1(0.5)$ \\
\hline \multicolumn{4}{|l|}{ Country of birth } \\
\hline Iraq & $38(25.0)$ & $25(36.2)$ & $63(28.5)$ \\
\hline Gulf countries & $27(17.7)$ & $11(15.9)$ & $38(17.1)$ \\
\hline Syria & $30(19.7)$ & $8(11.5)$ & 38 (17.1) \\
\hline Egypt & $20(13.1)$ & 7 (10.1) & $27(12.2)$ \\
\hline North African & $13(8.5)$ & $4(5.7)$ & $17(7.6)$ \\
\hline USA & $13(8.0)$ & $4(5.7)$ & $17(7.6)$ \\
\hline Yemen & $6(3.9)$ & $7(10.1)$ & $13(5.8)$ \\
\hline France & $1(0.5)$ & $2(0.9)$ & $3(1.4)$ \\
\hline Canada & $2(0.9)$ & - & $2(0.9)$ \\
\hline Libya & - & $1(0.6)$ & $1(0.5)$ \\
\hline Mauritania & $1(0.5)$ & - & $1(0.5)$ \\
\hline Somalia & $1(0.5)$ & - & $1(0.5)$ \\
\hline \multicolumn{4}{|c|}{ Primary language/s spoken at home } \\
\hline Arabic and English & $76(50.3)$ & $31(44.9)$ & $107(48.6)$ \\
\hline Only Arabic & $58(38.4)$ & $35(50.7)$ & $93(42.2)$ \\
\hline Only English & 15 (9.9) & $3(4.3)$ & $18(8.2)$ \\
\hline French & $1(0.5)$ & - & $1(0.5)$ \\
\hline Fulani & $1(0.5)$ & - & $1(0.5)$ \\
\hline \multicolumn{4}{|c|}{ Have a family member who smokes } \\
\hline Spouse & $34(22.3)$ & $6(8.6)$ & $40(18.1)$ \\
\hline Sibling/s & 75 (49.3) & 15 (21.7) & $90(40.7)$ \\
\hline Father & $101(66.4)$ & $25(36.2)$ & $126(57.0)$ \\
\hline Mother & $33(21.7)$ & $5(7.2)$ & $38(17.1)$ \\
\hline
\end{tabular}




\subsection{Cigarette Smoking Use Profile}

Experimentation with cigarettes started at an early age (Table 2). More than one fourth initiated smoking between the ages of $13-15$, and $65.7 \%$ reported that their fathers smoked as they grew up. Most of the smoker's self-reported smoking on a daily basis (81.3\%), and on average they smoked ten cigarettes per day. When the participants were asked "How many cigarettes did you smoke last week?”, more than $40 \%$ reported smoking 60 cigarettes. When asked about their most preferable type of cigarette, more than half preferred smoking "light cigarettes”; menthol cigarettes were second (36.1\%) to light cigarettes as the most preferred type, and almost $12 \%$ reported switching to a different type to help them to quit smoking. The average number of attempts to quit was 2.2 (SD 4.7). When participants were asked "how many times have you made a serious attempt to quit smoking in the last two years?” the average was only one attempt (SD 1.4). Also, 38\% of smokers never completely quit cigarettes while only $1 \%$ quit smoking for less than two weeks. Finally, participants were asked about their confidence in their perceived readiness to quit smoking. On a scale of 0 to 10 , the mean was 5.0 (SD 2.7).

\subsection{Attitudes and Beliefs about Smoking}

In regards to whether or not participants believed that smoking has general harmful effects, more than half of the smokers said no (59.3\%) while less than one third of them were concerned about the harmful effects of smoking on their health. The most frequently reported reason for smoking was prestige (54.6\%) followed by a desire to be socially accepted in the new culture (51.3\%). Only $21.7 \%$ of the smokers received advice and information about the hazards of their smoking status from their physicians. The majority (54.6\%) of smokers received the information about hazards to their health from the media. Non-smokers were asked about their reasons for not smoking. Of the 69 respondents, 56 self-reported religion as the most common reason. Other reasons included saving money $(\mathrm{n}=28)$, being raised by non-smoker parents $(n=26)$, self-discipline $(n=8)$, harmful effects on health $(n=7)$, and disliking the smell $(n=6)$. The chisquare test with a 0.05 significance level showed significant differences among smokers and non-smokers, with non-smokers having negative attitudes toward smoking (Table 3).

Table 2. Cigarette smoking profile $(\mathrm{n}=152)$.

\begin{tabular}{|c|c|c|c|}
\hline \multirow[b]{2}{*}{ Age when started smoking } & n (\%) & & n (\%) \\
\hline & \multicolumn{3}{|c|}{ Smoking frequency } \\
\hline Below 10 & $3(2.1)$ & Pack or more a day & $21(14.0)$ \\
\hline $10-12$ & $10(6.8)$ & Half pack a day & $49(32.6)$ \\
\hline $13-15$ & $38(26.1)$ & Few times most days & $39(26.0)$ \\
\hline Above 15 & $95(65.1)$ & Few times each week & $20(13.3)$ \\
\hline Smoking pattern & & Few times each month & $2(1.3)$ \\
\hline Daily & $118(81.3)$ & Few times in the last 12 months & $6(4.0)$ \\
\hline Occasionally & $27(18.6)$ & Types of cigarettes smoked & \\
\hline Number of cigarettes smoked daily (mean, SD) & $10(6.6)$ & Light & $56(42.1)$ \\
\hline \multirow[t]{2}{*}{ Number of cigarettes smoked last week (mean, SD) } & $57.5(42.6)$ & Regular & $29(21.8)$ \\
\hline & & Menthol & $48(36.1)$ \\
\hline \multicolumn{4}{|c|}{ Have you ever switched from one brand to another to reduce the amount of nicotine and tar? } \\
\hline Yes & & & $53(39.8)$ \\
\hline No & & & $80(60.2)$ \\
\hline \multicolumn{4}{|l|}{ I switched to a different brand to help me quit smoking } \\
\hline Yes & & & $28(12.6)$ \\
\hline No & & & $193(87.3)$ \\
\hline \multicolumn{4}{|l|}{ Do you buy cigarettes by } \\
\hline Pack & & & $67(50.7)$ \\
\hline Carton & & & $51(38.6)$ \\
\hline Other & & & $14(10.6)$ \\
\hline As you grew up did your father smoke regularly? & & & $92(65.7)$ \\
\hline As you grew up did your mother smoke regularly? & & & $19(14.3)$ \\
\hline
\end{tabular}


Table 3. Attitude and beliefs regarding smoking $(n=221)$.

\begin{tabular}{|c|c|c|}
\hline & $\begin{array}{c}\text { Current smoker }(\mathrm{n}=152) \\
\mathrm{n}(\%)\end{array}$ & $\begin{array}{c}\text { Non-smoker }(\mathrm{n}=69) \\
n(\%)\end{array}$ \\
\hline Smoking is harmful to health & $62(40.7)$ & $57(82.6)^{*}$ \\
\hline Are you concerned about the harmful effect smoking may have on your health? & $39(25.6)$ & $53(79.2)^{*}$ \\
\hline Do you have a "no smoking" sign at the workplace? & 105 (69.5) & $14(20.8)$ \\
\hline What do you believe makes people smoke? & & - \\
\hline Stress & $83(54.6)$ & $46(66.6)^{*}$ \\
\hline Prestige & $39(25.6)$ & $28(40.1)^{*}$ \\
\hline Pleasure & $78(51.3)$ & 37 (53.6) \\
\hline Social acceptance & $40(26.3)$ & $18(26.1)$ \\
\hline Other & $13(8.5)$ & $7(10.1)$ \\
\hline Source of information on obtaining health hazards of smoking & & - \\
\hline School & $68(44.7)$ & $20(28.9)^{*}$ \\
\hline Doctor & $33(21.7)$ & $29(42.0)^{*}$ \\
\hline Media & $83(54.6)$ & $40(57.9)$ \\
\hline Other & $13(8.5)$ & $2(2.8)$ \\
\hline
\end{tabular}

${ }^{*} \mathrm{p}<0.05$.

\subsection{Effect of Acculturation on Tobacco Use}

Acculturation indicators were examined in relation to the increase in the daily number of cigarettes smoked using linear regression. The age at which an individual moved to the US and the number of years an individual had lived in the US were significantly associated with an increase in the number of cigarettes smoked on a daily basis $(\mathrm{F}=3.4, \mathrm{p}<0.00)$ - (Table 4). Further analysis of acculturation in relation to the risk of not considering quitting was performed using logistic regression. The longer one had lived in the US (OR $=0.93$, CI: 0.87, 0.98) and the older one was when he/she had moved to the US $(\mathrm{OR}=0.93$, CI: $0.88,0.98)$ represented significant contributing factors to the least number of quit attempts.

\section{DISCUSSION}

Cigarette Smoking rates were higher among the study sample than the general population of the state of Virginia 22\% [5]. This finding was consistent with previous studies that assessed smoking prevalence among Arab immi- grants. Some of these studies followed different sampling approaches, which were representative of the community studied $[6,15,37]$. It is worth noting that the prevalence in these three studies was higher than the national average but still lower than what was found in our study. This could be explained by the fact that some of these studies used random sampling techniques within the respective studied populations. Further exploration of smoking prevalence among Arab immigrants in Richmond with a randomly selected sample could confirm the actual prevalence. However, there are no reasons to believe that Arab immigrants in Richmond would be different from their counterparts throughout USA.

Among the smokers in our sample, many initiated smok- ing at an early age. It is quite well known that experimentation with smoking at an early age increases the risk of being a dependent smoker [38]. Our findings are congruent with similar studies conducted in their Middle Eastern countries of origin [39].

Many smokers in this study had the desire to quit and attempted to quit. In another study, more than $70 \%$ were interested in quitting but lacked the tools [34]. It is possible that the smokers within the study sample were not getting the adequate support from their health care providers in order to quit; however, we do not have the data to support this claim. We also found that some of them reported switching to different types of cigarettes, such as menthols, in an attempt to help them quit as indicated through the results. (The question asked was "Did you switch to any other form of tobacco in order to quit like light or menthol brands?”) The smokers in the study sample were not likely to be aware of the resources that could have helped them quit. Lack of awareness of resources to quitting is evident in Arab immigrants. This preliminary study did not have a representative population of Arab immigrants in Virginia, thus we could not draw conclusions on the tobacco profile of this population.

Acculturation indicators measured in this study were found to be positively correlated with the number of smoked cigarettes per day, as well as the number of attempts to quit by Arab immigrants. The more they stayed in USA, the more they increased their number of smoked cigarettes and attempts to quit every year. Additionally, it was reported that they maintained behaviours of their ethnic background and spent more time with other Arab immigrants. This is consistent with the literature that asserts that more acculturated immigrants smoke more cigarettes per day than less acculturated 
Table 4. Acculturation indicators predicting number of cessations attempts and number of daily smoked cigarettes.

\begin{tabular}{|c|c|c|c|c|c|}
\hline \multicolumn{2}{|c|}{ Variables } & DF & Sum of squares & F ratio & $p$ value \\
\hline \multicolumn{2}{|c|}{ Language spoken at home } & 3 & 153.76093 & 1.2512 & 0.2950 \\
\hline \multicolumn{2}{|c|}{ First learned language } & 1 & 6.94769 & 0.1696 & 0.6813 \\
\hline \multicolumn{2}{|c|}{ Years in US } & 1 & 389.32958 & 9.5040 & $0.0026^{*}$ \\
\hline \multicolumn{2}{|c|}{ Age moved to US } & 1 & 577.97229 & 14.1090 & $0.0003^{*}$ \\
\hline Predictions & Odds ratio & Lower CL & Upper CL & Reciprocal & \\
\hline Years in US & 0.935256 & 0.878379 & 0.987119 & 1.0692258 & \\
\hline Age Moved to US & 0.935458 & 0.886487 & 0.980461 & 1.0689954 & \\
\hline
\end{tabular}

${ }^{*} \mathrm{p}<0.05$.

immigrants [29]. The reason for this can only be hypothesized. Smokers might believe that smoking will make them more accepted in the new culture. Also, moving to the US at an older age was a predictor of increasing the number of cigarettes smoked per day but was not significant when considering the number of serious quit attempts. The serious quit attempts seemed to have increased every year as the individual smoker stayed in USA, irrespective of their age of moving to the US. Collectively, it could be inferred that the daily smoking may have increased either as a secular trend of smoking more as one ages or, as other research indicated [15], being more acculturated could increase an immigrant's daily consumption of cigarettes. This echoes the addictive nature of nicotine, but on the flip side of this, the attempts to quit increased as exposure to the US (host) environment increased. This echoes the possible smoking denormalizing effect of the US environment on the Arab immigrants. This denormalizaion effect might have led the Arab immigrants in our study to have more serious attempts to quit. There is not much literature that explores the effect of acculturation on the health of Arab immigrants in relation to smoking, despite the understanding that during the previous decade this ethnic group might have been subject to related health disparities and discrimination because of the September 11 terrorist attacks [40].

These findings are consistent with the findings of other research that shows that there could be a negative acculturation effect or a positive acculturation effect in relation to smoking and other risk behaviours among different ethnic groups [24,29]. This depends on the behaviour being assessed. Not much research has been done in this arena, which does present an opportunity for more qualitative research in order to interpret the results behind these significant findings. Such research could then hopefully be used to better shape the future of tobacco control interventions for Arab immigrants.

\subsection{Limitations}

This study used a non-random sample, so it does not reflect the actual prevalence among Arab immigrants in Richmond, VA. We could not explore the effect of acculturation on smoking prevalence. There was no previous data on Arab immigrants in the Richmond metro area, and attempting a community based assessment would have been inherently difficult for an exploratory study.

The acculturation effect was assessed using a rough proxy measure and not a proper psychometric tool. The fact that this rough indicator is used in many studies does not eliminate the fact that it probably did not have a high degree of precision.

\subsection{New Contributions to the Literature}

This study explores the acculturation indicators that are believed to have an impact on the smoking prevalence in populations such as the one examined. This study has great significance in attracting the attention to the health disparities that Arab immigrants in the Richmond metro area are facing in terms of higher prevalence of tobacco use and diminished access to cessation aids. This creates an opportunity to promote tailored cessation interventions for Arab Immigrant communities. Thus, these interventions should take into consideration the specific profiles that Arab immigrants have in terms of the knowledge, attitudes, and effects of acculturation on their smoking habits.

\subsection{Disclosures}

Author(s) have provided signed confirmations to the publisher of their compliance with all applicable legal and ethical obligations in respect to declaration of conflicts of interest, funding, authorship and contributionship, and compliance with ethical requirements in respect to treatment of human and animal test subjects. If this article contains identifiable human subject(s), author(s) were required to supply signed patient consent prior to publication. Author(s) have confirmed that the published article is unique and not under consideration nor published by any other publication and that they have consent to reproduce any copyrighted material. The peer 
reviewers declared no conflicts of interest.

\section{ACKNOWLEDGEMENTS}

This study was supported by a grant award from the Virginia Tobacco Settlement Foundation.

\section{REFERENCES}

[1] World Health Organization (2005) World Health Organization tobacco free initiative. Regional databases (Eastern Mediterranean Region).

http://www.who.int/TFI/countryprofile-part6.htm

[2] US Department of Health and Human Services (2004) Smoking and health: Report of the advisory committee of the surgeon general of the public health service. US Public Health Service, Washington DC.

[3] US Department of Commerce Economic and Statistics Administration, US Census Bureau (2003) United States Census 2000.

[4] US Department of Health and Human Services (2000) Healthy People 2010. Government Printing Office, Washington DC.

[5] Kahende, J., Teplinskaya, A., Malarcher, A., Husten, C. and Maurice, E. (2007) State-specific prevalence of cigarette smoking among adults and quitting among persons aged 18-35 years-United States, 2006. Morbidity \& Mortality Weekly Report, 56, 993-996.

[6] Jamil, H., Templin, T., Fakhouri, M., Rice, V.H., Khouri, R. and Fakhouri, H. (2009) Comparison of personal characteristics, tobacco use, and health status in Chaldean, Arab American, and non-Middle Eastern White adults. Journal of Immigrant and Minority Health/Center for Minority Public Health, 11, 310-317. doi:10.1007/s10903-008-9125-7

[7] Kulwicki, A. and Rice, V. (2003) Arab American adolescent perceptions and experiences with smoking. Public Health Nursing, 20, 177-183. doi:10.1046/j.0737-1209.2003.20304.x

[8] Centres for Disease Control (CDC) (2012) Fact sheet: Smoking and tobacco use. http://www.cdc.gov/tobacco/data_statistics/fact_sheets/ad ult_data/cig_smoking/index.htm

[9] Rice, V. and Kulwicki, A. (1992) Cigarette use among Arab immigrants in the Detroit metropolitan area. Public Health Reports, 107, 589-594.

[10] Rudmin, F. (2009) Constructs, measurements and models of acculturation and acculturative stress. International Journal of Intercultural Relations, 33, 106-123. doi:10.1016/j.ijintrel.2008.12.001

[11] Lechuga, J. (2008) Is acculturation a dynamic construct: The influence of method of priming culture on acculturation. Hispanic Journal of Behavioural Sciences, 30, 324339. doi:10.1177/0739986308319570

[12] Newman, J. and Sahak, Z. (2012) Purchasing patterns of migrant groups: The impact of acculturation on ethnocentric behaviours. Journal of Applied Social Psychology, 42, 1551-1575.
[13] Taras, V. (2012) Instruments for measuring acculturation. http://people.ucalgary.ca/ taras/ private/Acculturation S urvey_Catalogue.pdf

[14] Barry, D. (2005) Measuring acculturation among male Arab immigrants in the United States: An exploratory study. Journal of Immigrant Health, 7, 179-184. doi:10.1007/s10903-005-3674-9

[15] Al-Omari, H. and Scheibmeir, M. (2009) Arab immigrants' acculturation and tobacco smoking. Journal of Transcultural Nursing, 20, 227-233. doi:10.1177/1043659608330353

[16] Schwartz, S., Weisskirch, R., Zamboanga, B., CastilloL, H.L., Huynh, Q., Park, I., Donovan, P., Kim, S., Vernon, M., Davis, M. and Cano, M. (2011) Dimensions of acculturation: Associations with health risk behaviours among college Students from immigrant families. Journal of Counselling Psychology, 58, 27-41. doi:10.1037/a0021356

[17] Lara, M., Gamboa, C., Kahramanian, M.I., Morales, L.S. and Hayes Bautist, D.E. (2005) Acculturation and Latino health in the United States: Review of the literature and its sociopolitical context. Annual Review of Public Health, 26, 367-397. doi:10.1146/annurev.publhealth.26.021304.144615

[18] Timothy, P., Johnson, B., VanGeest, J. and Cho, Y. Ik (2002) Migration and substance abuse: Evidence from the US national health interview survey. Substance Use \& Misuse, 37, 941-972.

[19] Lee, L., Nguyen, S. and Tsui, H. (2011) Interview language: A proxy measure for acculturation among Asian Americans in a population-based survey. Journal of Immigrant and Minority Health, 13, 244-252. doi:10.1007/s10903-009-9278-z

[20] Himmelgreen, D., Pérez-Escamilla, R., Martinez, D., Bretnall, A., Eells, B., Peng, Y. and Bermúdez, A. (2004) The longer you stay, the bigger you get: Length of time and language use in the US are associated with obesity in Puerto Rican women. American Journal of Physical Anthropology, 125, 90-96. doi:10.1002/ajpa.10367

[21] Cruz, T., Marshall, S., Bowling, J. and Villaveces, A. (2008) The validity of a proxy acculturation scale among US Hispanics. Hispanic Journal of Behavioural Sciences, 30, 425-446. doi:10.1177/0739986308323653

[22] Berry, W. (1980) Acculturation as Varieties of Adaptation. In: Padilla, A.M., Ed., Acculturation: Theory, Models and Some New Findings, Westview Press, Boulder, 9-25.

[23] Choney, K., Berryhill-Paapke, E. and Robbins, R. (1995) The acculturation of American Indians: Developing frameworks for research and practice. In: Ponterotto, J.G. Casas, J.M., Suzuki, A. and Alexander, M., Eds., Handbook of Multicultural Counselling, Sage Publications, Thousand Oaks, 73-92.

[24] Choi, S., Ranking, S., Steward, A. and Oka, R. (2008) Effects of acculturation on smoking behaviour in Asian Americans: A meta analysis. Journal of Cardiovascular Nursing, 23, 67-73.

[25] Carabaloo, R.S. and Lee, C.W. (2006) Tobacco use among Mexicans and their descendants in the United States. Salud Pública de México, 46, 241-250. 
http://www.aaiusa.org/arabamericans/22/

[26] Fagan, F., Augustson, P., Backinger, E., O’Connell, C., Vollinger, M., Kaufman, R., Gibson, A. and Quit, T. (2007) Attempts and intention to quit cigarette smoking among young adults in the United States. American Journal of Public Health, 97, 1412-1420. doi:10.2105/AJPH.2006.103697

[27] Young, Y., Hopkins, R., Smith, R. and Hogarth, M.D. (2010) Smoking cessation: The potential role of risk assessment tools as motivational triggers. Postgraduate Medical Journal, 86, 26-33.

[28] Ward, Y., Swan, M.M. and Jack, L.M. (2001) Self-reported abstinence effects in the first month after smoking cessation. Addictive Behaviors, 26, 311-327. doi:10.1016/S0306-4603(00)00107-6

[29] Marin, M., Perez-Stable, E. and Marin, B. (1989) Cigarette smoking among San Francisco Hispanics: The role of acculturation and gender. American Journal of Public Health, 79, 196-198. doi:10.2105/AJPH.79.2.196

[30] US Census Bureau (2012) The Arab population. http://www.census.gov/prod/2003pubs/c2kbr-23.pdf 2003

[31] Zakaria, N. (2000) The effects of cross-cultural training on the acculturation process of the global workforce. International Journal of Manpower, 21, 492-510. doi:10.1108/01437720010377837

[32] Baker, O. (2005) Relationship of parental tobacco use, peer influence, self-esteem, and tobacco use among YemeniAmerican adolescents: Mid range theory testing. Ethnicity and Disease, 15, 69-71.

[33] Rice, V., Weglicki, L., Templin, T., Hammad, A., Jamilm H. and Kulwickim A. (2006) Predictors of Arab American adolescent tobacco use. Merrill-Palmer Quarterly, 52,
327-342. doi:10.1353/mpq.2006.0020

[34] Templin, T., Rice, H., Gadelrab, H., Weglicki, L., Hammad, A., Kulwicki, A., Al-Omran, H., Al-Faouri, I., Baker, O., Jamil, H., Thompson, F., Dakroub, M. and Abou-Mediene, S. (2005) Trends in tobacco use among Arab-American adolescents: Preliminary findings. Ethnicity and Disease, 15, 65-68.

[35] Haddad, L. and Petro-Nustas, W. (2006) Predictors of intention to quit smoking among Jordanian university students. Canadian Journal of Public Health, 97, 9-13.

[36] MacNee, C. and Talsma, A. (1995) Predictors of progress in smoking cessation. Public Health Nursing, 12, 242248. doi:10.1111/j.1525-1446.1995.tb00143.x

[37] Maziak, W., Ward, K.D., Afifi Soweid, R.A. and Eissenberg, T. (2004) Tobacco smoking using a waterpipe: A reemerging strain in a global epidemic. Tobacco Control, 13, 327-333. doi:10.1136/tc.2004.008169

[38] Abou-Mediene, S., Rice, V.H., Jamil, H., Templin, T., Hammad, A., Weglicki, L., Kulwicki, A., Al-Faouri, I., Al-Omran, H., Baker, O., Dakroup, M. and Thompson, F. (2005) A comparison of psychosocial factors and tobacco use among Arab and Arab-American Adolescents: Preliminary findings. Ethnicity and Disease, 15, 60-65.

[39] Harrabi, I., Maaloul, J.M., Gaha, R., Kebaili, R., Maziak, W. and Ghannem, H. (2010) Comparison of cigarette and waterpipe smoking among pupils in the urban area of Sousse, Tunisia. La Tunisie Medicale, 88, 470-473.

[40] Knishkowy, B. and Amitai, Y. (2005) Water-pipe (narghile) smoking: A merging risk behaviour. Pediatrics, 116, e113-e119. doi:10.1542/peds.2004-2173 